\title{
FOCUSING ON DIGITALIZATION: CORE FOR NATIONAL ECONOMIC POLICIES TO COMPETE GLOBALLY
}

\section{EKA SEPASHVILI}

\author{
Associate professor \\ Ivane Javakhishvili Tbilisi State University, Georgia \\ eka.sepashvili@tsu.ge
}

\begin{abstract}
The contemporary ultimate goal for any national government is to insure science-based economic development to achieve higher standard of leaving for citizens. Technological achievements are significant factors for modern global economic development. The new industrial revolution is fundamentally different from the old ones. The current one - named as fourth industrial revolution-creates the new environment of digital world. Fourth Industrial Revolution is the key issue on contemporary development agenda in academic, political and economic circles. Against the constant development of the information technologies, more and more business processes, products, goods, and services are impacted by innovations. This process entails the continuous evolution of business models, which eventually are becoming more and more digitalized.

However, the digital development remains still an on-going process even in condition of COVID pandemic rather than a reality of every national economy. National Governments have to redouble their efforts to create better and larger infrastructure for the digital economy to grow. The ability of expanding business through physical infrastructure cannot be considered for granted in the digital economy. Not only physical infrastructure is enough for further digitalization. The creation of an ecosystem that systematically allows top innovations to be advanced globally still remains a key policy goals. Consequently, the national economic policy aiming at rising the welfare of the country has to pay particular attention to resource, mainly labour and capital, efficiency by providing basic infrastructure for facilitation of digitalization and increasing their expenditure on R\&D to enable businesses and individuals effectively use novelties for creating competitive advantages to take stronger position in global markets.
\end{abstract}

KEYWORDS: DIGITALIZATION, ECONOMIC POLICY, GLOBAL COMPETITIVENESS.

For citation: Sepashvili, E., (2021). Focusing on Digitalization: Core for National Economic Policies to Compete Globally. Globalization and Business. 12, 13-20. https://doi.org/10.35945/gb.2021.12.001

\section{INTRODUCTION}

In contemporary world digital technologies gaining speed to be incorporated in every spare of our lives over the globe. Against the constant development of the information technologies, more and more business processes, products, goods, and services are impacted by innovations. This process entails the continuous evolution of business models, which eventually are becoming more and more digitalized. In this article, we will not try to analyze whether it is good or bad, or what positive and negative consequences it may have. The article points to the fact that the world is slowly moving towards digital processes, and this process should be followed by national economies. Consequently, the promotion of digital processes should be an integral part of any national economic policy. It goes without saying that policy-making must also take into account the difficult task of avoiding negative aspects as much as possible and simultaneously making available all the benefits of introducing digital technologies.
Current pandemic caused by COVID-19 Virus accelerated the process of digitalization worldwide. The process is not restricted just to the use of digital means and tools. It has also encouraged and supported significant deepening of digital transformation creating the numerous ways in which governments, businesses, and individuals are suing the digital devises to conduct daily tasks previously done mostly personally. The reality created by the pandemic has shown that many things can be done online, using digital technologies. The debate over the future of artificial intelligence (Al) and its impact on the workplaces has been filled with new evidence and arguments. However, we emphasize that these new arguments and evidence are not only positive and/or negative. Most of them are contradictory and serve to demonstrate the complexity of the problem rather than to draw any concrete conclusions.

The contemporary ultimate goal for any national government is to insure science-based economic development to achieve higher standard of leaving for citizens. At the same time it should adequately face the challenges of globalization 
targeting at positive benefits that global economy offers to players meanwhile avoiding negative impact that globalized world imposes on national developments. Technological achievements are significant factors for modern global economic development. Fourth Industrial Revolution is the key issue on modern development agenda in academic, political and economic circles (Schwab, 2016). Success of the country in science and research significantly defines the level of national welfare. However, increasing of resources efficiency depends rather on usage of knowledge and technology than on simple existing of well-equipped higher educational institutions and/ or highly skilled workers (Sepashvili, 2019b). Thus, just exiting of higher educational system and generating researchers do not mean higher positions in R\&D (Gagnidze, 2016).

\section{LITERATURE REVIEW}

A quick glance on current global development proves that unprecedented economic growth since late 90s of the past century till 2007, before global economic crisis, was accompanied by rapid expansion and knowledge development of digital technologies. Both, quantitative and qualitative changes in IT equipment, which made able to broadly spread digital electronic devises among wide range of populations, cheaper and broader access to the internet, consumer-friendly usages, easier access to different data bases and etc. accelerated diffusion of knowledge and science into modern goods and services.

Production processes are determined by the combination of technology and devices along the whole value chain. Computer-driven systems are becoming more and more common to monitor and conduct physical processes. Digital technologies create a virtual copy of the physical world. Manufacturing industries easily integrate physical objects with /into the information network, "allowing real-time adaptation in the future" (Smit et al., 2016).

Digital technologies dramatically reduce the cost of business operations and transactions, and thus, significantly improve the efficiency of economy. Unprecedented spread of digital enterprises entails the new practice of social, mobile, analytics and cloud (SMAC) technologies to achieve greater productivity. At the same time, unprecedented growth of digital consumers, in its turn, boost even wider usage of SMAC technologies and thus, lead to a new era of digital economy and digital world (Gazzola et al., 2021; Mermanisvili, 2019). In contemporary global development digital technologies force business to adapt novelties to survival in the transformed global industrial space against the tough international competition (Lekashvili, 2019; Sepashvili, 2020b).

The rapid development of digital firms is main characteristics of the Fourth Industrial Revolution. Against the constant development of the information technologies, more and more business processes, products, goods, and services are impacted by innovations that boost policy-makers, economic actors and business operators to evolve accordingly and eventually will become more and more digitalized. In the digital economy, the focus is on the production of intellectual products, which is associated with high capital expenditure (Gogorishvili, 2019; Gazzola et al, 2017).

In particular, digital technologies influence development and introduction of innovation in numerous ways. Digital technologies expanded research tools and methods through more precise implication of huge amounts of data and broader participation of researchers, who currently have excellent opportunity for distance cooperation. Due to the Digital technologies new services and products are developed and invented as well as old products and services are acquiring new, digital dimension and thus, additionally advance quality and achieve competitive cost advantages (Mella, 2019). At the same time, digital technologies make faster and easier market integration through significant dropping communication costs and increasing matching efficiency, which in its turn increases competitive advantage of those who use this novelties (Sepashvili, 2019a). They support to easily overcome entry barriers by offering online services, like globally accessible cloud computing and online marketing platforms to wider range of enterprises and start-ups both in internal markets and foreign markets (Bedianashvili 2018, Mermanishvili, 2020). Big data and the digital methods of their analysis equip economic actors and business with the possibility to precisely target products so they more thoroughly align with consumer preferences grounded on more accurate information about the latters.

Forming a modern globally competitive economy and reaching permanent economic growth and high level of welfare is barely possible without the recognition and realization of an innovation-based policy approach. Innovative development, knowledge- and science-based growth nowadays is impossible without digital technological development and transformation. At the same time, policy approach ensuring relevant volume of investments in technology, R\&D alone cannot ensure higher levels of development without appropriate digital network readiness. New technologies, devices, equipment, and remote services require that the corresponding physical infrastructure and relevant skills be available to widely use the opportunities offered by digital technologies. The economic policy has to focus on efficient synergy of digital infrastructure with human capital through continuous encouraging and facilitating skill development and education of workers and individuals. The example of advanced economies illustrates that education is a key factor for achieving global competitiveness. As jobs continue to modificate, education requires to be regarded as a life-long process. Curricula and teaching as well as learning methods have to be constantly developed and renewed. Such approach is critically important for economic policy in modern areas such as artificial intellect, bio-engineering, remote services and etc. (Sepashvili, 2019b).

Business and government should cooperate to accelerate and enforce efforts to invest in innovative digital resolutions to motivation social impact. Government should play more active role in the processes as sustainable digital economy will depend on rapidly evolving governance regulations and relevant legislation that allow societies to trust and feel secure when facing the numerous evidences of impact of digital 
technologies and respond quickly to changing circumstances.

Every country is trying to keep abreast of the rapid development of digital technologies. Therefore, government have to support by sound economic policy, which is aiming at continuous looking for investors and high-tech specialists who are able to move across different industries to digital platforms. Digital readiness is indeed a scourge for conventional competitive advantage in the economy. The policy measures vary according to the countries but the common for all of them is creating suitable and relevant basic infrastructure and legislative base. These are two main pillars that are policy-makers' responsibility (Dimchenko et al., 2021; Sepashvili, 2020a).

Ability of national economy to respond to digitalization is a measure of the success in international competition that will encourage the stimulation of the countries' economies (Shkarlet et al., 2020). Digitalization brought a significant technological change in the economy (Curran, 2017). The openings and challenges offered by digital renovation and following production advanced technologies rise the importance of policies that can assist countries take advantage of these new technologies (OECD, 2019).

However, it is still too early to observe accurate data on impact imposed by COVID pandemic on the process of digitalization and government actions to respond by supporting appropriate infrastructure. National accounts and annual reports of different international organization are only starting tracking and showing comparable figures and evidences. So far, the rapid development of remote working in locked-down economies, as well as the replacement of physical meetings and events by virtual conferencing have demonstrated that the potential to digitize a number of activities (including education, for example) was generally far greater than anticipated, though proved to be not so efficient as it was regarded from the very beginning. However, the subsequent practices will continue to influence the way of work, learn, compete, and cooperate for governments, business and individuals (Bedianashvili, 2021; Dimchenko, 2021).

Digitalalization requires both digital competence and digital culture of the population. Therefore, introducing the digital process in business operations is essential and should be taken on the board completely (Jakubik \& Berazhny, 2017). While focusing on increasing of labor productivity, resource efficiency, and business profitability, policy-makers have to change approaches to adapt the new reality (Bolte et al. 2018). Digital advancement can be also regarded as promotion of electronic interaction or to say in other words so called virtual leadership (Saputra, 2020). It means to create appropriate digital environment that facilitates to higher level of resource effectiveness and labor productivity (Roman et al. 2018). The digital technologies will become the part of nearly every industry. Though, it is contemporary economic opportunity (Kane et al., 2016), that nations have to use and adapt with.

All national economies have to meet new challenges for the next decades. Industry 4.0 is accompanied massive processes of digitization translated into automatization and robotozation of major production processes. Thus, it requires economy to ensure relevant level of digital performance. Therefore, policy-makers need to assess their maturity in facing this new paradigm of global economic development trend. The methodology to measure digital readiness is comparatively new. Readiness assessment deals with knowledge, skills, and availability of physical infrastructure. It means to measure the level of digitization of the country using for processing and utilizing resources as well as the level of efficiency and effectivness (Pai et al., 2020).

Digital technology represents a key driver of innovation and modern economic growth globally and has greatly contributed to national competitiveness (Sepashvili, 2020; Nesterova et al., 2018;). At the present stage, the main task of competitive national economies is to develop policies that create and develop technological innovations and thus, become prepared to meet the Fifth Industrial Revolution (Manta, 2019).

\section{RESEARCH RESULTS}

Physical infrastructure, appropriate electronic devises and relevant skills are necessary to widely apply digital technologies. No innovations could be developed without the appropriate physical network infrastructure, which connects persons, productions, devices and countries. Those countries that are adjust at expansion of physical infrastructure enabling digital operations' well-functioning will maintain and/or gain additional advantages in international competitiveness.

It's worth emphasizing, that more and more innovation are based on digital technologies and business models, which can initiative economic and social gains from ICTs if managed in a smart way. The means and ways through which the businesses adopt ICTs is decisive for leveraging them for development, so supporting and encouraging businesses to fully utilize the powers of digital technologies should be a priority for national policy actions.

Since 2001, the World Economic Forum in cooperation with INSEAD and Cornell University publishes The Global Information Technology Report to estimate and measure these factors, namely the drives of information and communication technologies. The index is called Networked Readiness Index (NRI). It has evolved since 2001 and currently measures and assess the networked readiness of the major countries using wide range of indicators. The indicators describe four main aspects of the country readiness for digital economy: 1 . overall environment for usage and creation of the technology covering political, regulatory, business, and innovation factors; 2 . Physical infrastructure of the network to use ICT and appropriate skills; 3 . technology adoption/usage by the government, the private sector/business, and individuals/ consumers; and 4. the economic and social impact of the new technologies.

According the Global Information Technology Report 2016, the Network Readiness Index (NRI) was measured through 53 indicators formulating the following 4 pillars: 


\section{Environment subindex}

- Political and regulatory environment (9 indicators);

- Business and innovation environment ( 9 indicators).

2. Readiness subindex

- Infrastructure (4 indicators);

- Affordability (3 indicators);

- Skills (4 indicators).

3. Usage subindex

- Individual usage (7 indicators);

- Business usage (6 indicators);

- Government usage (3 indicators).

4. Impact subindex

- Economic impacts (4 indicators);

- Social impacts (4 indicators).

The calculation of the overall NRI score is based on following aggregations of scores: individual indicators are combined to gain pillar scores, which are then combined get sub-index scores. Sub-index scores are in turn combined to produce a country's overall NRI score. Networked readiness is improving almost everywhere in the world, with a clear upward trend in performance over the globe across all regions.

Recent developments showed that underlying concept of NRI has to be modified to reflect the key essence of the readiness. Renewed NRI model includes 30 other general or technology-specific indices and reflects new surveys' results. The most recent tendency is that, the only assessment of physical infrastructure, based on its presence, affordability, adoption, and relevance (e.g. the existence of local language content) and the level of personal adoption, do not provide accurate country-level data that is enough to allow fair rankings. A curtain number of observation proves growing importance of the human factor of network readiness. The new model attempts to capture the influence of people's choices concerning technology and governance for economic growth. It tries to reveal the impact of network readiness to the achievement of SDGs broader goals, representing main challenge for the nations.

The new NRI model measures a harmonious integration of people and technology, as the technologies are continuously evolving and becoming more intelligent. Interaction between individuals and technologies will increase in most fragments of governance, business and society. To support the efficiency of this integration, appropriate governance and relevant economic policy is needed to address problems dealing with security, trust, and inclusion. At the same time, the main issues do not take into consideration the level of welfare. To say in other word to meet the SDGs and ensure a positive impact on the economy.

Thus, the new NRI model was developed that incorporate three major principles:

1. to maintain continuity of the major components of the previous years' $\mathrm{NRI}$;

2. to reflect the current to ICT arrangement that were not adequately captured in the 2016 NRI model;

3. to take into consideration the future technology development trends in the NRI model.

Based on these considerations, a new NRI model was de- veloped that maintains the four pillars: Technology, People, Governance, and Impact. Each pillar includes three subpillars:

\section{Technology}

Technology is at the core of the network economy. This pillar seeks to assess the level of technology that correlated to a country's participation in the global economy.

- Access: The level of ICT in countries, including communications infrastructure and affordability.

- Content: The type of digital technology formed in countries, and the content/applications that can be arranged locally.

- Future Technologies: The level to which countries are equipped for the future of the network economy and new technology development trends.

\section{People}

- This pillar seeks to for the level of the access, resources, and skills to use technologies productively. It deals with the application of ICT at three levels of analysis: governments, businesses, and individuals.

- Individuals: the degree individuals use technology and how they use their skills to participate in the network economy.

- Businesses: the degree businesses use ICT and take part in the network economy.

- Governments: How governments use and advance in ICT for the benefit of the population.

\section{Governance}

This pillar seeks to determine how favorable the national environment is for a country's participation in the network economy, based on issues of trust, regulation, and inclusion.

- Trust: safety of individuals and firms in the context of the network economy, as well as the trusting behavior of the population.

- Regulation: The government regulations promoting participation in the network economy.

- Inclusion: The digital divides where governance can address inequality based on gender, disabilities, and socio-economic status.

\section{Impact}

The pillar seeks to evaluate the improvement of the growth and well-being of society and the economy through the economic, social, and human impact of participation in the network economy.

- Economy: The economic effect of participating in the network economy.

- Quality of Life: The social influence of participating in the network economy.

- SDG Contribution: how participation in the network economy affect health, education, and environment and contributes to achieve the SDGs.

The main deviations in NRI 2020 concern the two subpillars: Trust (Governance) and SDG Contribution (Impact). 
The Trust sub-pillar has been theoretically and essentially reinforced by including: trust environment and trust behavior. This approach is partially based on a study about digital trust (Chakravorti et al. 2017). The SDG Contribution sub-pillar has been redefined in a way that each indicator is clearly linked to a particular SDG. Currently, the sub-pillar consists of five indicators that each embodies one SDG: SDG 3, Good Health and Well-Being; SDG 4, Quality Education; SDG 5, Gender Equality; SDG 7, Affordable and Clean Energy; and SDG 11, Sustainable Cities and Communities. Finally, 60 indicators were identified to settle these 12 sub-pillars.

For comparison we look through the data for selected countries, namely for top three countries, some EU state members, especially the format socialist and soviet countries and the EU eastern partnership countries (former soviet countries) to track tendency and the prospect for future development.

Comparison of 2015-2020 data shows that some countries maintain their leading positions, though changed the rank slightly. For instance, Sweden, ranked as third position in 2015-2016, advanced and holed steady first positions in 2019-2020, meanwhile Denmark demonstrates steady improvement and being at 15 and 11 positions in 2015 and 2016, accordingly, significantly improved its performance and holds second position in 2020 after having 6th position in 2019. The same tendency in observed with certain countries as well, e.g. Germany 13 and 15 in 2015 and 2016 accordingly, advanced at 9th position in 2019-2020; France showed steady advancement from 26 and 24 in 2015 and 2016, progressed to the 18 and 17 position in 2019-2020. The same situation is for Italy, Bulgaria and Ukraine. At the same time, some countries worsen their positions after the ranking concept changed slightly and included human impact more broadly in measurement methodology. The examples of such countries which we select, are Singapore, Japan, Estonia, Latvia, Russian Federation, Turkey, Azerbaijan, and Georgia. It's worth to mentioning that, some of these worsening positions were steady in 2015-2016, e.g. Singapore, Japan, Estonia, Russian Federation, Turkey had firmly positions at 1, 10, 22, 41, 48 accordingly both in 2015 and 2016, but Positions deteriorated in 2019-2020 and demonstrate less favorable conditions for digital transformations.

Data shows that advanced countries are leaders in the index positions, including the performance on all pillars of the NRI: Technology, People, Governance, and Impact. No wonder that Technologies have significant constructive influence on national economic developments and on their ability to meet the SDGs. But be achieve this the effective governance mechanisms have to be in place to support the integration of technologies with the three key stakeholders - governments, businesses, and individuals.

Economies over the globe are all the different stage of the digital transformation. Moreover, their economic policy priorities are varying and therefore, creating diverse picture of digital global pictures. Hence, no wonder that despite the fact that digitization in influencing everywhere and everything, the benefits it generates are disseminated unevenly.

The technological gap is still a key concern at the global level. High-income countries demonstrate the most futurereadiness in all dimensions and especially in technology.

Table 1. Network Readiness Rank by Country 2015-2020

\begin{tabular}{|l|c|c|c|c|c|c|c|c|}
\hline & \multicolumn{9}{|c|}{ Rank } & \multicolumn{5}{c|}{ Pillars' rank in 2020 } \\
\hline countries & 2015 & 2016 & 2019 & 2020 & technology & people & governance & Impact \\
\hline Sweden & 3 & 3 & 1 & 1 & 2 & 4 & 4 & 3 \\
\hline Denmark & 15 & 11 & 6 & 2 & 5 & 1 & 2 & 5 \\
\hline Singapore & 1 & 1 & 2 & 3 & 10 & 5 & 13 & 1 \\
\hline Germany & 13 & 15 & 9 & 9 & 7 & 12 & 12 & 7 \\
\hline Japan & 10 & 10 & 12 & 15 & 21 & 6 & 23 & 11 \\
\hline France & 26 & 24 & 18 & 17 & 18 & 20 & 15 & 12 \\
\hline Estonia & 22 & 22 & 23 & 23 & 24 & 21 & 11 & 29 \\
\hline Lithuania & 31 & 29 & 31 & 29 & 32 & 23 & 21 & 39 \\
\hline Italy & 55 & 45 & 34 & 32 & 30 & 36 & 33 & 28 \\
\hline Slovakia & $\mathrm{n} / \mathrm{a}$ & $\mathrm{n} / \mathrm{a}$ & 35 & 35 & 34 & 49 & 30 & 35 \\
\hline Latvia & 33 & 32 & 39 & 37 & 38 & 39 & 28 & 42 \\
\hline Bulgaria & 73 & 69 & 49 & 46 & 43 & 55 & 44 & 52 \\
\hline Russian Federation & 41 & 41 & 48 & 48 & 49 & 31 & 65 & 60 \\
\hline Armenia & 58 & 56 & 62 & 55 & 42 & 42 & 76 & 65 \\
\hline Turkey & 48 & 48 & 51 & 57 & 58 & 53 & 48 & 81 \\
\hline Ukraine & 71 & 64 & 67 & 64 & 62 & 65 & 58 & 79 \\
\hline Belarus & $\mathrm{n} / \mathrm{a}$ & $\mathrm{n} / \mathrm{a}$ & 61 & 65 & 68 & 62 & 71 & 56 \\
\hline Azerbaijan & 57 & 53 & 70 & 66 & 60 & 57 & 87 & 58 \\
\hline Georgia & 60 & 58 & 68 & 68 & 59 & 63 & 64 & 94 \\
\hline Moldova & 78 & 71 & 66 & 71 & 74 & 69 & 74 & 66 \\
\hline
\end{tabular}

Source: Global Information Technology Report 2016; The Network Readiness Report 2019, Portulans Institute; The Network Readiness Report 2020, Portulans Institute. 
Obviously, the group of high-income countries leads the NRI rank. One of the strongest indicators of NRI performance is a country's income level. Due to the tendency, that highincome countries have usually invested profoundly in their technology infrastructure and thus, boosting both access and content, no wonder that they maintain better positions and manage to better use the opportunities offered by technological innovations. The clear correlations can be observed if we look through the showings concerning GDP per capita both in nominal US dollar or PPP US dollar (see the table 2).

The data of both tables demonstrate a significant and strong positive correlation between digital readiness and GDP per capita. As data shows NRI ranks rises alongside with income level. Henceforth, the top NRI performers are mainly high-income economies, whereas the bottom NRI performers are mostly low-income economies and lower-middle-income and upper-middle-income countries placed in between. However, despite this clear correlation, government spending on R\&D as 5 of GDP reveals, that juts volume of financial resources that are directed to research and innovations is not itself the only factor that support country's readiness for digitalization. As figures show in the table 2, some countries with less percentage of GDP spent of R\&D, nevertheless hold upper position in NRI rank in comparison with other countries. For instance, Singapore is spending just $1,94 \%$ of its GDP, but is ahead of such countries as Germany, France, which spend on R\&D much higher present of their GDP, 3.09\%, and 2, 20\% accordingly. Lithuania (29) is ahead of Italy (32), Russia (48) and Turkey (57) in terms of NRI rank though spends smaller amounts on R\&D as percentage of GDP $0.94 \%$ in comparison of these countries $(1,4 \%, 0.99 \%$ and $0.96 \%)$ and though in total volume of financial recourse it ranks higher positions if we take glance at GDP per capita level of these countries Lithuania 19997 USD, Russia 10127 USD and Turkey 8538 USD, but France showing for GDP per capita represents much impressive amount 38625 USD, which lives space for further consideration for policy makers.

Hence, the more important is to support and facilitate the connection of individuals and business with digital infrastructure, electronic devises and on-line services offered by government agencies and businesses alongside with development of physical infrastructure and relevant legislative regulations ensuring security, safety and stability of digital process. Such synergy encourages and boosts national firms and economic actors to produce new products and services that are compatible in the global markets and supports them to achieve and maintain sound positions as well as to generate higher incomes translated into improved welfare of nation overall. This means stronger competitiveness of the country.

\section{CONCLUSION}

Emergence and unprecedented wide spread of digital technologies together with such new technologies as genengineering, artificial intellect, telecommunication, new materials, microelectronics, bio-technology and etc. dictates

\section{Table 2. GDP per capita by Country}

\begin{tabular}{|l|c|c|c|c|c|c|c|}
\hline \multirow{2}{*}{ Country } & \multicolumn{2}{|c|}{ GDP per capita (nominal) } & \multicolumn{2}{|c|}{ GDP per capita (PPP) } & R\&D expenditure & NRI in \\
\cline { 2 - 6 } & 2018 & 2019 & 2018 & 2019 & 2020 & as of DGP 2018 & 2020 \\
\hline Sweden & 53747 & 55815 & 54589 & 51610 & 51925 & 3.34 & 1 \\
\hline Denmark & 57218 & 59830 & 61391 & 59822 & 60908 & 3.06 & 2 \\
\hline Singapore & 100051 & 101376 & 66189 & 65233 & 59797 & 1.94 & 3 \\
\hline Germany & 54457 & 56052 & 47639 & 46259 & 45723 & 3.09 & 9 \\
\hline Japan & & & & & & 3.26 & 15 \\
\hline France & 46605 & 49435 & 41631 & 40494 & 38625 & 2.20 & 17 \\
\hline Estonia & 36358 & 38811 & 23258 & 23660 & 23312 & 1.43 & 23 \\
\hline Lithuania & 35832 & 38214 & 19081 & 19455 & 19997 & 0.94 & 29 \\
\hline Italy & 42816 & 44197 & 34520 & 33190 & 31676 & 1.40 & 32 \\
\hline Slovakia & 32575 & 34178 & 19428 & 19329 & 19156 & 0.83 & 35 \\
\hline Latvia & 30645 & 32204 & 17805 & 17836 & 17620 & 0.63 & 37 \\
\hline Bulgaria & 22601 & 24561 & 9424 & 9738 & 9975 & 0.77 & 46 \\
\hline Russian Federation & 28764 & 29181 & 11371 & 11585 & 10126 & 0.99 & 48 \\
\hline Armenia & 13015 & 14220 & 4220 & 4623 & 4267 & 0.19 & 55 \\
\hline Turkey & 28139 & 27875 & 9370 & 9042 & 8538 & 0.96 & 57 \\
\hline Ukraine & 12629 & 13361 & 3097 & 3659 & 3726 & 0.47 & 64 \\
\hline Belarus & 19331 & 19943 & 6330 & 6663 & 6411 & 0.61 & 65 \\
\hline Azerbaijan & 14545 & 15001 & 4740 & 4794 & 4214 & 0.18 & 66 \\
\hline Georgia & 14594 & 15637 & 4723 & 4769 & 4278 & 0.30 & 68 \\
\hline Moldovan & 12665 & 13574 & 4234 & 4499 & 4551 & 0.25 & 71 \\
\hline
\end{tabular}


national governments to take special measures to encourage appropriate national policy including but not limiting to physical infrastructure, generating knowledge, facilitating for innovations business and individuals and thus enabling firms and market actors to produce new products and services that will be compatible at the global markets. Of course, the policy means and tools as well as national models, ways and practices differ according countries and their resources such as financial, human, capital expenditures on research and development and etc.

Today more than ever future of countries depends on how national governments can coordinate businesses and individuals to deal with digital technologies. This political goal equally concerns variety of issues such as physical infrastructure for internet networks, regulatory frameworks, business readiness, consumer skills and etc. Policymakers have to develop such policy measures that support basic infrastructural development in closely cooperation with other stakeholders - business, academicians, individuals, - to promptly implement universal long-term goals for modern technological development and lead in adapting environment to ensure that ICTs deliver maximum benefit for national development.

Digitalization has been an advantage to the global econo- my. However, the digital development remains still an on-going process even in condition of COVID pandemic rather than a reality of every national economy. National Governments have to redouble their efforts to create better and larger infrastructure for the digital economy to grow. The ability of expanding business through physical infrastructure cannot be considered for granted in the digital economy. Not only physical infrastructure is enough for further digitalization. The creation of an ecosystem that systematically allows top innovations to be advanced globally still remains a key policy goals.

Consequently, the national economic policy aiming at rising the welfare of the country has to pay particular attention to resource, mainly labour and capital, efficiency by providing basic infrastructure for facilitation of digitalization and increasing their expenditure on R\&D to enable businesses and individuals effectively use novelties for creating competitive advantages to take stronger position in global markets. The economic policy has to focus on efficient synergy of digital infrastructure with human capital. Such synergy encourages and boosts national firms and economic actors to produce new products and services that are compatible in the global markets and supports them to achieve and maintain sound positions as well as to generate higher incomes translated into improved welfare of nation overall.

\section{REFERENCES:}

Baller, S., Dutta, S., \& Bruno Lanvin, B. (Eds). (2016). The Global Information Technology Report 2016. Innovating in the Digital Economy. World Economic Forum \& INSEAD. The Business School for the world. Johnson Cornel University.

Bedianashvili, G. (2018). Knowledge Economy, Innovative Entrepreneurial Policy and Culture: Systemic View. Materials of the International Scientific-Practical Conference: Modern tendencies of development of economy and economic science. Paata Gugushvili institute of economics, Ivane Javakhishvili Tbilisi State University, Tbilisi, 28-32.

Bedianashvili, G., \& Maglakelidze A. (2021). The Digital Economy and Business in the Conditions of Pandemic, The materials of the International Scientific Conference: Social Sciences for Regional Development 2020, part 3. Issues of economics, Daugavpils University, 26-37.

Chakravorti, B., Bhalla, A., \& Chaturvedi, R. Sh. (2017, July 12). 60 Countries' Digital Competitiveness, Indexed. Harvard Business Review.

Curran, D. (2017). Risk, innovation, and democracy in the digital economy. European Journal of Social Theory.

Dimchenko, O. (2021), Organizational and economic support of innovative development of public utilities: conceptual provisions. Danish Scientific Journal, 2 (46/2021), 39-47.

Dymchenko, O., Sepashvili, E., \& Slavata, D. (2021), Analysis of Existing Approaches to the Regions Competitiveness Determining. Internet conferences of KhNUMG named after OM Beketova. Kharkov, Ukraine, 28 January, 2021.

Gagnidze, I. (2016). The Impact of Entrepreneurial Universities on the Innovative Development of Economy, Conference Proceedings: Strategic Imperatives of Modern Management, KNEY, Kiev, 186-192. http://wiki.kneu.kiev.ua/ bitstream/2010/20956/1/186-192.pdf

Gazzola, P., Colombo, G., Pezzetti, R., \& Nicolescu, L. (2017). Consumer empowerment in the digital economy: Availing sustainable purchasing decisions. Sustainability, 9(5), 693.

Gazzola, P., Grechi, D., Papagiannis, F., \& Marrapodi, C. (2021). The Sharing economy in a digital society: youth consumer behavior in Italy. Kybernetes. 50(1), 147-164.

Gogorishvili, I. (2019). State Economic Policy for Regulating Digital Economy in Small Countries. Università Degli Studi DI Pavia. AB 57. 2019. http://bslab-symposium.net/Pavia-2019/BSLAB-\%20Book\%20of\%20Abstract-Pavia- 2019.pdf.

http://bslab-symposium.net/Pavia-2019/BSLAB-\%20Book\%20of\%20Abstract-Pavia-2019.pdf

Jakubik, M., \& Berazhny, I. (2017). Rethinking Leadership and It's Practices in the Digital Era. Paper presented at the Management International Conference, Monastier di Treviso (Venice), Italy, May 24-27, 471-483.

Kane, G. C., Palmer, D., Phillips, A. N., Kiron, D., \& Buckley, N. (2016). Aligning the Organization for Its Digital Future. MITS Loan Management Review, Research Report. Digital Evolution. 58180. London: Deloitte University Press. 
Lekashvili, E. (2019), Management on Innovations in Georgian Higher Educational Insitutions: Key Problems with teaching Economic Science. Marketing and Management of Innovations. 1, 281-293. http://doi.org/10.21272/mmi.2019.1-23;

Mella, P. (2012). Business and non-Business Value Creating Organizations in the "Information and Internet Age". Economia Aziendale Online, (1), 1-22.

Mella, P. (2019). Quality, a Key Value Driver in Value Based Management. Economia Aziendale Online, 9(4), $439-462$.

Mermanishvili, T. \& Sepashvili, E. (2020), Digital Signature: A key Tool for Technological Transformation in Global Economy, ISBN: 9788890824296 Book of Abstracts of the 7th Business Systems Laboratory International Symposium "SocioEconomic Ecosystems", Alicante, Spain January, 2020. 188-195.

Mermanishvili, T. (2019). Digital Marketing -a Modern Technological Tool for Gaining Competitive Advantages in Global Markets. Business Systems Laboratory 6th International Symposium, Borders without Borders: Systematic Frameworks and their Applications for Sustainable Well-being in the Global Era. University De Pavia, Italy,134-139;

Nesterova, Z. V., Solosichenko,T., \& EMakovkina, E. I. (2018). Digitalization Process as a Factor Increasing Austrian Competitiveness. Advances in Social Science, Education and Humanities Research. In 2nd International Scientific Conference on New Industrialization: Global, National, Regional Dimension (SICNI). Amsterdam: Atlantis Press, vol. 240.

OECD. (2019). Public Governance Policy Papers, Digital Government Index. OECD Public Governance Policy Papers, 03. Paris: OECD.

Otilia, M. (2019). The Role of Competitiveness on the Sustainability of the National Real Economy. The Journal Contemporary Economy 4, 138-146.

Pai, P. R., Navab, A.,\& Sureshc, A. S. (2020). Factors of Digital Readiness and Its Impact on Adoption of Industrial Internet of Things. Journal of Xi'an University of Architecture \& Technology, 12: 5703.

Roman, A. R., Montgomery, V., Wart, V., Wang, X. H., Liu, C., Kim, S. \& McCarthy, A. (2018). Defining E-leadership as Competence in ICT-Mediated Communications: An Exploratory Assessment. Public Administration Review 79, 853-866.

Saputra, N., \& Saputra, A. M. (2020). Transforming into Digital Organization by Orchestrating Culture, Leadership and Competence in Digital Context. GATR Global Journal of Business \& Social Science Review 8: 208-16.

Schwab, K. (2016). The Fourth Industrial Revolution. Geneva: World Economic Forum.

Sepashvili, E. (2016) Globalized World Economy, Innovations and National Policies for Economic Growth. Book of Abstracts of 4th Business Systems Laboratory International Symposium: Governing Business Systems. Theories and Challenges for Systems Thinking in Practice. Vilnius, 174-176.

Sepashvili, E. (2019), Digital Technologies and E-banking: the Future of Global Economy, Kyiv National Economic University, International Scientific and Practical Conference proceeding, November 20-22, 45-52. Kiev, Ukraine

Sepashvili, E. (2019). Knowledge Triangle: Innovation Policy Approach to Strengthen National Competitiveness, Business Systems Laboratory 6th International Symposium, Borders without Borders: Systematic Frameworks and their Applications for Sustainable Well-being in the Global Era. University De Pavia, Italy, 134-139, http://bslab-symposium.net/Pavia-2019/ BSLAB-\%20Book\%20of\%20Abstract-Pavia-2019.pdf

Sepashvili, E. (2020a). Supporting Digitalization: Key Goal for National Competitiveness in Digital Global Economy. Economia Aziendale Online. 11 (2), 191-198.

Sepashvili, E. (2020b). Digital Chain Policy of Contemporary Global Economy: e-commerce Evolution Through e-banking and e-signature. Economia Aziendale Online, 11(3), 239-249.

Shkarlet, S., Dubyna, M., Shtyrkhun, K., \& Verbivska, L. (2020). Transformation of the Paradigm of the Economic Entities Development in Digital Economy. Wseas Transactions on Enovironment and Development.

Smit, J., Kreutzer, S., Moeller C., \& Carlberg M. (2016). Industry 4.0. Policy Department A: Economic and Scientific Policy, European Parliament.

The Network Readiness Report 2019, Portulans Institute.

The Network Readiness Report 2020, Portulans Institute. 